\title{
The Effect of Locally Delivered Doxycycline in the Treatment of Chronic Periodontitis. A Clinical and Microbiological Cohort Study
}

\author{
Ioannis Ioannou ${ }^{1}$, Nikolaos Dimitriadis ${ }^{1}$, Konstantinos Papadimitriou ${ }^{1}$, Ioannis Vouros ${ }^{1}$, Dimitra \\ Sakellari $^{1}$, Antonis Konstantinidis ${ }^{1}$
}

${ }^{1}$ Department of Preventive Dentistry, Periodontology and Implant Biology, School of Dentistry, Aristotle University of Thessaloniki, Greece

\author{
Corresponding Author: \\ Ioannis Ioannou \\ 26-30 Meg. Alexandrou Str, Kalamaria 55134, Thessaloniki \\ Greece \\ Phone: +302310444467 \\ Fax: +302310444467 \\ E-mail: $\underline{\text { iioann@otenet.gr }}$
}

\begin{abstract}
Objectives: To evaluate the efficacy of locally delivered doxycycline as an adjunct to non-surgical treatment with the use of an ultrasonic device compared to scaling and root planing using hand instruments, by means of clinical and microbiological criteria.

Material and Methods: Thirty three patients with chronic periodontitis participated in this cohort study and were divided into two groups. Patients in control group received scaling and root planing using hand instruments, whereas patients in control group received ultrasonic debridement and $8.8 \%$ doxycycline gel was applied after initial therapy and at 3 months at preselected sites. Clinical recordings concerning probing pocket depth, clinical attachment level, plaque index and gingival bleeding index were performed at baseline, 3 and 6 months after baseline. Subgingival samples were analysed using the "checkerboard" DNA-DNA hybridisation technique for Porphyromonas gingivalis, Tannerella forsythia and Treponema denticola.

Results: Both treatments resulted in significant improvement in all clinical recordings. Six months after the treatment a statistically significant decrease was observed for Porphyromonas gingivalis in both of groups and Treponema denticola in the control group $(\mathrm{P}<0.05)$. No inter-group differences were observed $(\mathrm{P}<0.05)$.

Conclusions: Both treatment modalities provided comparable clinical and microbiological results in the treatment of chronic periodontitis.
\end{abstract}

Keywords: chronic periodontitis; doxycycline; root scaling; root planing; debridement; cohort studies.

\footnotetext{
Accepted for publication: 31 July 2010

To cite this article:

Ioannou I, Dimitriadis N, Papadimitriou K, Vouros I, Sakellari D, Konstantinidis A. The Effect of Locally Delivered Doxycycline in the Treatment of Chronic Periodontitis. A Clinical and Microbiological Cohort Study.

J Oral Maxillofac Res 2010 (Oct-Dec);1(4):e1

URL: http://www.ejomr.org/JOMR/archives/2010/4/e2/v1n4e1ht.pdf

doi: $10.5037 /$ jomr.2010.1401
} 


\section{INTRODUCTION}

Periodontal diseases (PDs) constitute a series of infections caused by the microorganisms that colonize sites at or below the gingival margin. These infections commonly lead to periodontal inflammation and often result in the destruction of the supportive periodontal tissues. The organisms that cause these diseases reside in unique structures termed biofilms that offer partial protection to the colonizing organisms from the defense mechanisms of the host, as well as from the antimicrobials used for treatment [1]. The primary goal of conventional periodontal therapy is the alteration of subgingival biofilms present on periodontally diseased sites that could be associated with the progressive destruction of the supportive periodontal tissues [2]. It is well documented that mechanical therapy combined with oral hygiene instruction is effective in achieving this goal $[\underline{3}, \underline{4}]$. Comparisons between manual and power-driven approaches to plaque and calculus removal and their effects on clinical outcomes show that both are equally effective $[\underline{5}, \underline{6}]$.

Over the last 3 decades, locally delivered, anti-infective pharmacological agents have been employed in attempts to treat local bacterial infections associated with gingivitis and periodontitis. Techniques of the local anti-infective therapy with pharmacological agents have varied widely, both in the methods of drug delivery and in the pharmacological agents employed. Drug delivery methods initially included oral rinses, then irrigation devices, followed by subgingival irrigation using syringes or powered irrigation devices. More recently, drug delivery has involved the incorporation of antiinfective drugs in sustained-release vehicles enabling subgingival administration of the drug. These sustainedrelease vehicles overcome many of the problems inherent in other drug delivery methods, such as rinsing or irrigation [7]. These systems exhibit shortcomings including inadequate or unpredictable penetration of the periodontal pocket by the drug, rapid clearance of the drug from the pocket resulting in inadequate time of the exposure of subgingival bacteria to the drug and poor patient compliance $[\underline{8}, 9]$. Local antiinfective therapy has also employed an eclectic variety of pharmacological agents from topical antiseptics to broad-spectrum antimicrobials. Chlorhexidine, tetracycline, minocycline, metronidazole, doxycycline, as well as other antimicrobials and antiseptics have been used in several forms. Two systematic reviews with the meta-analysis of data $[7,10]$ from studies evaluating the effect of locally delivered antimicrobials as an adjunctive therapy to scaling and root planing (SRP) revealed evidence of improved clinical outcomes in terms of the greater PD reduction and/or clinical attachment gain compared to SRP alone. This was particularly true with the use of tetracyclines, although the clinical significance remains questionable.

The aim of the present study was to compare the clinical and microbiological effects of scaling and root planing with hand instruments to a non-surgical treatment with the use of an ultrasonic device combined with the application of locally delivered doxycycline.

\section{MATERIAL AND METHODS}

The subjects for the present cohort study were recruited from the Postgraduate Clinic of the Department of Preventive Dentistry, Periodontology and Implant Biology, School of Dentistry, Aristotle University of Thessaloniki, Greece between September 2004 and March 2005. The Ethical Committee of the School of Dentistry of Aristotle University of Thessaloniki, Greece approved the study protocol and all participating patients signed an informed consent at the beginning of the study.

The patients $(n=20)$ comprising the control group were the same as in our previous study [11]. Another twenty adult patients with generalised advanced chronic periodontitis [12] were recruited for the study following a screening examination of 28 patients by one examiner (I.V.), which included full mouth probing and radiographic examination, in order to comprise the control group. The inclusion and exclusion criteria were as follows:

\section{Inclusion criteria}

(i) Subjects must be adults between 18 and 70 years of age.

(ii) Subjects must have at least 4 sites with initial probing pocket depth (PPD) $\geq 5 \mathrm{~mm}$ in at least 2 quadrants, demonstrating bleeding on probing.

(iii) Subjects must not have received any periodontal treatment during the previous 6 months.

\section{Exclusion criteria}

(i) Compromised medical condition.

(ii) Systemic antibiotics during treatment or for the last 3 months.

(iii) Ongoing drug therapy that might affect periodontal therapy.

(iv) History of allergy to doxycycline hyclate or other tetracyclines.

(v) Requirement for prophylactic antibiotic cover of the patient.

(vi) Use of the chlorexidine mouthwash or any other antimicrobial agent. 
(vii) Female patients must not be pregnant or lactating.

Clinical examinations were performed at the screening examination, 3 and 6 months after treatment and involved assessment of PPD, clinical attachment level (CAL), gingival bleeding index (GBI) [13] and plaque index [14]. The measurements of PPD and CAL were performed at six sites per tooth with a manual periodontal probe (Hu-Friedy PCP-UNC 15, Hu-Friedy, Chicago, IL, USA) to the nearest millimetre. Prior to the study, the intra-examiner variability test was carried out to assess the accuracy of examiner's measurements. In order to assure the reproducibility of measurements, all recordings regarding PPD and CAL were repeated after a period of 30 minutes. In the event of a difference of $>2 \mathrm{~mm}$ between the two measurements, a third measurement was performed at the respective site. The mean of pair of the two closer measurements was evaluated for further analysis.

The patients fulfilling the necessary prerequisites were assigned into 2 groups of 20 patients each: control group (scaling and root planing with hand instruments - SRP) and experimental group (ultrasonic debridement + doxycycline - UD + DOXY). At all time points, the outcomes of research were assessed blind and the examiner (I.V.) was unaware of the kind of treatment the patient was receiving. The analysis of subgingival samples was performed by three of authors (I.I., N.D., K.P.) who were also unaware of the treatment that the patient had received (coded samples).

\section{Experimental design and treatment procedures}

At the screening examination, a full mouth measurements of clinical parameters were recorded and intraoral radiographs were taken. After a period of 1 week (baseline examination), subgingival plaque samples were taken from 6 preselected sites from each patient. The sites were selected according to their initial probing depth and were divided in 3 categories: (i) 2 sites with PPD $\leq 4 \mathrm{~mm}$ (shallow pockets), (ii) 2 sites with PPD $>4$ to $\leq 6 \mathrm{~mm}$ (moderate pockets) and (iii) 2 sites with PPD $>6 \mathrm{~mm}$ (deep pockets). No furcation, endo-periodontic defects or third molars were included in the study material. Microbiological sampling at the same sites, as at the baseline examination, and a full mouth clinical recordings were repeated at 3 and 6 months after the baseline.

At the same session, supragingival scaling was performed with hand instruments and ultrasonics, and oral hygiene instructions (OHI) were given by the examiner. The $\mathrm{OHI}$ included twice-daily tooth brushing, using the modified Bass technique, and oncedaily inter-dental cleaning with inter-dental brushes.
At the next appointment, two weeks after the baseline examination, the allocated intervention was initiated.

The treatment procedures in the control group were the same as described elsewhere [11]. Hand instrumentation of the whole dentition was performed at weekly intervals in three to four sessions by using Gracey Curettes under the local anaesthesia (SG 3/4, 11/12, 13/14 and After Five Curettes SAS 3/4, 11/12, 13/14, Hu-Friedy PCPUNC 15, Hu-Friedy, Chicago, IL, USA).

Patients of the experimental group received debridement of whole dentition in 3 - 4 sessions, under the local anaesthesia, at weekly intervals, utilizing a piezoelectric ultrasonic device (EMS Piezon ${ }^{\circledR}$, EMS, Nyon, Switzerland) with A and P instruments (Swiss InstrumentsPM, EMS, Nyon, Switzerland) under water irrigation. The tips were examined after every session and were discarded when worn out. The teeth were treated until a smooth, appropriately debrided surface was achieved. In the four deeper, preselected pockets 8.8\% doxycycline gel (Atridox ${ }^{\mathrm{TM}}$, Atrix Laboratories, Inc., Ft. Collins, CO, USA) was applied at the completion of therapy and after the first re-examination at 3 months.

In both groups the endpoint of the smoothness was judged by the supervisor (I.V.), who decided upon the completion of root instrumentation by using a periodontal probe (Hu-Friedy PCP 11, Hu-Friedy, Chicago, IL, USA) and an explorer (Hu-Friedy WilkinsTufts 17/23, Hu-Friedy, Chicago, IL, USA).

\section{Test drug}

The doxycycline gel (Atridox ${ }^{\mathrm{TM}}$, Atrix Laboratories, Inc., Ft. Collins, CO, USA) is a subgingival controlledrelease product composed of a two syringe mixing system. Syringe A contains $450 \mathrm{mg}$ of the ATRIGEL ${ }^{\mathbb{B}}$ Delivery system, which is a bioabsorbable, low viscosity polymeric formulation composed of $36.7 \%$ poly(DL-lactide) (PLA) dissolved in a biocompatible carrier of $63.3 \%$ N-methyl-2-pyrrolidone (NMP). Syringe B contains doxycycline hyclate, which is equivalent to $44 \mathrm{mg}$ doxycycline. The product, when mixed, is a pale yellow, viscous liquid with a concentration of $8.8 \%$ doxycycline hyclate. The two syringes are coupled together mixing the two components for 100 cycles. By the use of 23-gauge cannula attached to the delivery system the test product was slowly introduced into the periodontal pocket, starting from the base of pocket, until it reached the gingival margin. Following withdrawal of the cannula tip, a curette was used to pack any overflow of the drug down into the pocket. No periodontal dressing or adhesive was used. Upon contact with the crevicular fluid, the liquid product solidifies and then allows for 
controlled release of drug for a period of 7 days. The patients were instructed not to perform oral hygiene measures at the treated areas for 1 week.

\section{Microbiological evaluation}

After the isolation with cotton rolls, drying and removal of supragingival plaque, the subgingival samples were taken with a sterile Gracey curette (Hu-Friedy, Chicago, IL, USA), were subsequently placed individually in $200 \mu \mathrm{l}$ of TE buffer (Tris HCl $10 \mathrm{mM}$, EDTA $1 \mathrm{mM}$, $\mathrm{pH}=7.5)$ and stored after the treatment with an alkali solution $(0.5 \mathrm{M} \mathrm{NaOH})$ at $-4{ }^{\circ} \mathrm{C}$.

The microbiological samples were evaluated separately for 3 bacterial species using the "checkerboard" DNA-DNA hybridisation technique as described by Socransky et al. [15]. The subgingival species used for development of digoxigenin-labelled whole genomic probes were Porphyromonas gingivalis (FDC 381), Tannerella forsythia (FDC 338) and Treponema denticola (TD1).

\section{Data analysis}

CAL was set as the primary outcome variable. PPD, GBI and plaque index were considered as secondary outcomes. The data were analysed using the patient as a unit. The primary analysis was "per protocol" [16] and included all patients who attended the final examination. Data were entered into an Excel sheet database (MS Office Excel 2000; Microsoft Corporation, Redmond, WA, USA). Mean and standard error of the mean (SEM) were calculated for every parameter. Levene's test for the quality of error variance was applied in order to check the homogeneity of clinical parameters at the baseline. The analysis was made for plaque index, GBI, PPD and CAL based on full mouth measurements (the third molars were not included). A further analysis was performed for PPD and CAL for the three different categories, according to the initial pocket depth. The first category comprised pockets with initial pocket depth lesser or equal to $4 \mathrm{~mm}$, the second pockets with initial pocket depth $>4$ to $\leq 6 \mathrm{~mm}$ and the third pockets with pocket depth greater than $6 \mathrm{~mm}$.

Bacterial species were quantified following the formation of reference curve, which allowed the conversion of chemiluscent signals to total bacterial counts (Total Lab ${ }^{\mathrm{TM}}$ v2005, Nonlinear Dynamics Ltd, Newcastle upon Tyne, UK). The homogeneity of two groups at the baseline for microbiological parameters was checked using the Mann-Whitney test. Averaged bacterial scores from each subject were averaged for each group and compared at all time-points. A further comparison at the three examinations was made for the sites with initial PPD $>4 \mathrm{~mm}$ (moderate and deep pockets), which were those that received the drug in the control group.

The differences over time within groups for both clinical and microbiological results were analysed with the non-parametric test Wilcoxon Signed Ranks. The comparison between control and control group was performed using the Mann-Whitney test. The level of significance was set at $\mathrm{P}<0.05$. All statistical analysis was carried out with the aid of statistical software (SPSS version 12.0, SPSS Inc., Chicago, IL, USA).

\section{RESULTS}

At the baseline examination 40 patients entered the study (20 in the SRP group, 20 in the UD + DOXY group), from which 33 subjects completed the 6 month protocol (16 in the SRP group, 17 in the UD + DOXY group, mean age 50.46, range 37 - 69 years). Four patients did not return for any re-examination, while another three did not attend the final examination. One patient moved, three patients started work, preventing visits to the clinic and the other three were unwilling to finish the study for personal reasons. The flowchart of the patients is illustrated in Figure 1 and the characteristics of the patient sample that completed the study are summarised in Table 1. The initial statistical analysis revealed no statistical differences between the two groups at the baseline examination. The intra-examiner variability test demonstrated that the reproducibility of the measurements of PPD and CAL within $\pm 1 \mathrm{~mm}$ was $90 \%$. No adverse effects were reported by any of the patients.

An average of $69.1 \%$ of all pockets in the SRP group and $71.5 \%$ in the UD + DOXY group had initially PPD $\leq 4 \mathrm{~mm}$. The moderate pockets comprised 23\% and $21.4 \%$ of all pockets respectively. The deep pockets were $7.9 \%$ and $7.1 \%$ respectively. At the 6 month

Table 1. Epidemiological characteristics of the patient sample (Mean \pm SEM, per protocol analysis)

\begin{tabular}{lcc}
\hline & \multicolumn{2}{c}{ Patient groups } \\
\cline { 2 - 3 } & Control & Experimental \\
\hline $\mathrm{N}$ & 16 & 17 \\
Age (years) & $49.62 \pm 2.07$ & $52.9 \pm 2.12$ \\
Gender (male/female [\%]) & $50 / 50$ & $41.2 / 58.8$ \\
Smokers & $50 \%$ & $42.2 \%$ \\
Initial PPD (mm) & $3.91 \pm 0.21$ & $4.09 \pm 0.18$ \\
Initial CAL (mm) & $5.37 \pm 0.42$ & $5.24 \pm 1.44$ \\
\hline
\end{tabular}

$\mathrm{PPD}=$ probing pocket depth $\mathrm{CAL}=$ clinical attachment level. 


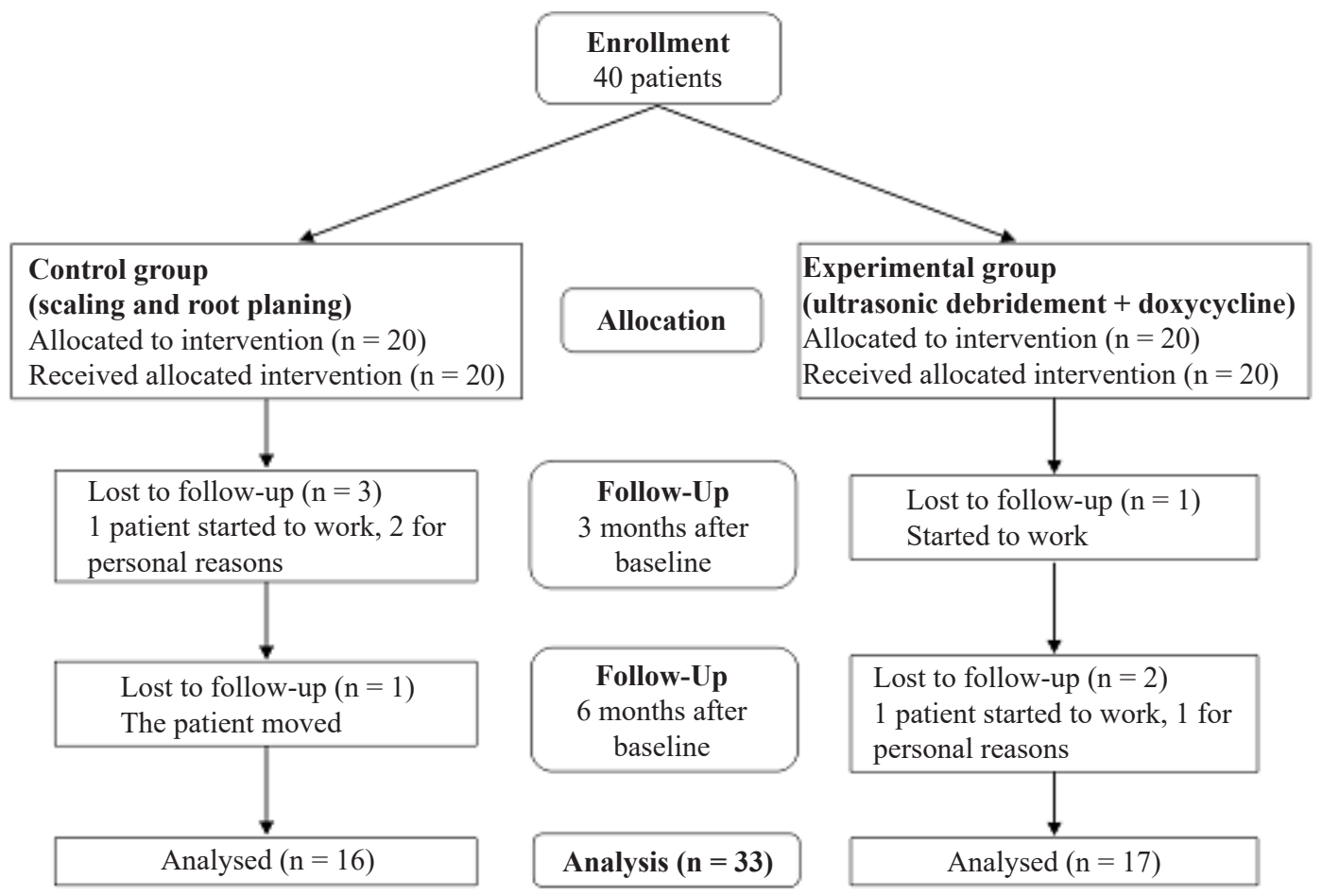

Figure 1. Flowchart of the patients throughout the study.

examination in the SRP group the shallow pockets represented $84.9 \%$, the moderate pockets $11.3 \%$ and the deep pockets only $3.8 \%$ of all pockets. In the UD + DOXY group the corresponding percentages were $84.2 \%, 12.4 \%$ and $3.4 \%$.

\section{Plaque index}

The oral hygiene status, as assessed by the plaque index, during the course of study is shown in Table 2. At the baseline the mean full-mouth plaque scores were $88 \%$ in the SRP group and $81 \%$ in the UD + DOXY group. A statistically significant decrease to $26 \%$ in the control group and to $37 \%$ in the control group was recorded at the 6 month examination (Wilcoxon Signed Ranks test, $\mathrm{P}<0.05)$. No statistically significant differences were observed between the two groups at any interval (Mann-Whitney test, $\mathrm{P}>0.05$ ).

\section{Gingival Bleeding Index (GBI)}

A statistically significant reduction in GBI scores was observed in both treatment groups following treatment. GBI indices also the improved following a similar pattern in both groups; at the 6 month re-examination the GBI was reduced from $59 \%$ to $33 \%$ in the SRP group and from $61 \%$ to $32 \%$ in the UD + DOXY group (Wilcoxon Signed Ranks test, $\mathrm{P}<0.05$, Table 2). No statistically significant difference in GBI between the two groups was observed at any examination interval (Mann-Whitney test, $\mathrm{P}>0.05$ ).

\section{Probing Pocket Depth (PPD)}

Changes in the PPD are presented in Table 3. A marked mean PPD reduction was observed for both treatment modalities at the 3 month re-examination

Table 2. Mean Plaque Index and Gingival Bleeding Index scores (Mean \pm SEM $[\mathrm{mm}]$ ) at different examination intervals for control and experimental group patients

\begin{tabular}{lccc}
\hline & Baseline & 3 months & 6 months \\
\hline Plaque Index & & & \\
\hline Control group & $0.88 \pm 0.03$ & $0.26 \pm 0.06^{\mathrm{a}}$ & $0.26 \pm 0.05^{\mathrm{a}}$ \\
Experimental group & $0.81 \pm 0.06$ & $0.35 \pm 0.03^{\mathrm{a}}$ & $0.37 \pm 0.04^{\mathrm{a}}$ \\
\hline Gingival Bleeding Index & & & \\
\hline Control group & $0.59 \pm 0.05$ & $0.32 \pm 0.04^{\mathrm{a}}$ & $0.33 \pm 0.05^{\mathrm{a}}$ \\
Experimental group & $0.61 \pm 0.05$ & $0.26 \pm 0.04^{\mathrm{a}}$ & $0.32 \pm 0.04^{\mathrm{a}}$ \\
\hline
\end{tabular}

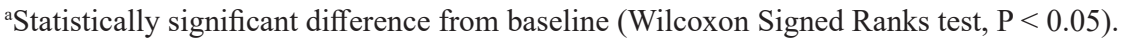


Table 3. Probing pocket depth (PPD) scores for the various PPD categories at different examination intervals for control and experimental group patients

\begin{tabular}{lccc}
\hline & \multicolumn{3}{c}{ Probing pocket depth (Mean \pm SEM $[\mathrm{mm}])$} \\
\hline \multicolumn{1}{c}{ PPD category/patient groups } & Baseline & 3 months & 6 months \\
\hline Shallow $(\leq \mathbf{4} \mathbf{~ m m})$ & & & \\
\hline Control $^{\mathrm{c}}$ & $2.90 \pm 0.10$ & $2.50 \pm 0.08^{\mathrm{a}}$ & $2.57 \pm 0.14^{\mathrm{a}}$ \\
Experimental & $2.76 \pm 0.09$ & $2.51 \pm 0.06^{\mathrm{a}}$ & $2.63 \pm 0.07^{\mathrm{b}}$ \\
\hline Moderate $(>\mathbf{4} \mathbf{t o} \leq \mathbf{6} \mathbf{~ m m})$ & & & \\
\hline Control & $5.39 \pm 0.05$ & $3.84 \pm 0.11^{\mathrm{a}}$ & $3.86 \pm 0.20^{\mathrm{a}}$ \\
Experimental & $5.33 \pm 0.04$ & $4.11 \pm 0.10^{\mathrm{a}}$ & $4.11 \pm 0.14^{\mathrm{a}}$ \\
\hline Deep $(>\mathbf{6} \mathbf{~ m m})$ & & & \\
\hline Control & $7.88 \pm 0.23$ & $5.17 \pm 0.20^{\mathrm{a}}$ & $4.74 \pm 0.31^{\mathrm{a}}$ \\
Experimental & $7.77 \pm 0.15$ & $5.94 \pm 0.20^{\mathrm{a}}$ & $5.61 \pm 0.14^{\mathrm{a}, \mathrm{b}}$ \\
\hline Overall & & & \\
\hline Control & $3.91 \pm 0.21$ & $3.03 \pm 0.13^{\mathrm{a}}$ & $3.03 \pm 0.19^{\mathrm{a}}$ \\
Experimental & $4.09 \pm 0.19$ & $3.15 \pm 0.11^{\mathrm{a}}$ & $3.17 \pm 0.12^{\mathrm{a}}$ \\
\hline
\end{tabular}

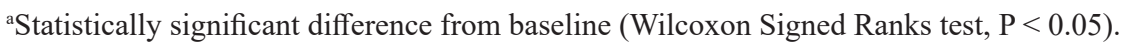

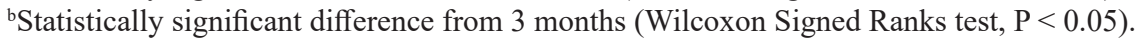

${ }^{\mathrm{c}}$ No statistically significant differences were observed between groups (Mann-Whitney test, $\mathrm{P}>0.05$ ).

( $0.88 \mathrm{~mm}$ for the SRP and $0.94 \mathrm{~mm}$ for the UD + DOXY group, Wilcoxon Signed Ranks test, $\mathrm{P}<0.05)$. During the following observation period ( 3 to 6 month examination) only minor changes were found. No statistically significant differences were observed between the two groups at any interval (Mann-Whitney test, $\mathrm{P}>0.05$ ).

The PPD measurements were further analysed for the three different categories of initial pocket depth.

For the shallow (PPD $\leq 4 \mathrm{~mm}$ ), the moderate A statistically significant improvement of CAL was
$(>4$ to $\leq 6 \mathrm{~mm})$ and the deep pockets (PPD $>6 \mathrm{~mm})$ the results are presented in Table 3 . In the deep pockets an additional, statistically significant reduction was observed in PPD between 3 and 6 months in the experimental group (Wilcoxon Signed Ranks test, $\mathrm{P}<0.05$, Table 3).

\section{Clinical Attachment Level (CAL)}

Table 4. Clinical Attachment Level scores for the various probing pocket depth categories at different examination intervals for control and experimental group patients

\begin{tabular}{|c|c|c|c|}
\hline \multirow[b]{2}{*}{ PPD category/Patients groups } & \multicolumn{3}{|c|}{ Clinical Attachment Level (Mean \pm SEM $[\mathrm{mm}])$} \\
\hline & Baseline & 3 months & 6 months \\
\hline \multicolumn{4}{|l|}{ Shallow $(\leq 4 \mathrm{~mm})$} \\
\hline Control $^{\mathrm{b}}$ & $4.45 \pm 0.35$ & $4.41 \pm 0.35$ & $4.36 \pm 0.36$ \\
\hline Experimental & $3.97 \pm 0.26$ & $3.93 \pm 0.20$ & $4.07 \pm 0.22$ \\
\hline \multicolumn{4}{|l|}{ Moderate $(>4$ to $\leq 6 \mathrm{~mm})$} \\
\hline Control & $6.93 \pm 0.26$ & $5.68 \pm 0.32^{\mathrm{a}}$ & $5.68 \pm 0.34^{\mathrm{a}}$ \\
\hline Experimental & $6.43 \pm 0.20$ & $5.52 \pm 0.20^{\mathrm{a}}$ & $5.71 \pm 0.17^{\mathrm{a}}$ \\
\hline \multicolumn{4}{|l|}{ Deep (>6 mm) } \\
\hline Control & $9.10 \pm 0.32$ & $7.04 \pm 0.32^{\mathrm{a}}$ & $6.55 \pm 0.44^{\mathrm{a}}$ \\
\hline Experimental & $8.83 \pm 0.32$ & $7.50 \pm 0.32^{\mathrm{a}}$ & $7.24 \pm 0.32^{\mathrm{a}}$ \\
\hline \multicolumn{4}{|l|}{ Overall } \\
\hline Control & $5.37 \pm 0.42$ & $4.87 \pm 0.37^{\mathrm{a}}$ & $4.78 \pm 0.40^{\mathrm{a}}$ \\
\hline Experimental & $5.24 \pm 0,44$ & $4.78 \pm 0,26^{\mathrm{a}}$ & $4.93 \pm 0,32$ \\
\hline
\end{tabular}

aStatistically significant difference from baseline (Wilcoxon Signed Ranks test, $\mathrm{P}<0.05$ ).

${ }^{b}$ No statistically significant differences were observed between groups (Mann-Whitney test, $\mathrm{P}>0.05$ ). 
revealed for both groups at the 3 month examination $(0.50 \mathrm{~mm}$ for the SRP group and $0.46 \mathrm{~mm}$ for the UD + DOXY group respectively, Wilcoxon Signed Ranks test, $\mathrm{P}<0.05$, Table 4$)$. No major changes were observed for both groups at the 6 month examination. Statistically significant differences between the two groups were not recorded at any interval (Mann-Whitney test, $P>0.05$ ). In the SRP group the 6 month result remained significantly better compared to the baseline score (Wilcoxon Signed Ranks test, $\mathrm{P}<0.05$ ), whereas in the UD + DOXY group the mean CAL score did not demonstrate a significant difference in comparison with the baseline value (Wilcoxon Signed Ranks test, $\mathrm{P}>0.05)$.

A similar analysis as for the PPD measurements was made for the CAL measurements as well. The results for the shallow, moderate and deep pockets are shown in Table 4. The differences between 3 and 6 month re-examinations and the baseline examination were statistically significant for the two groups (Wilcoxon Signed Ranks test, $\mathrm{P}<0.05)$, whereas no statistically significant, inter-group differences were observed (Mann-Whitney test, $\mathrm{P}>0.05$ ).

\section{Microbiological parameters}

In total, 594 microbiological samples were analysed. The results for all the investigated species and for all of the six sites per patient are summarised in Table 5 . At the 3 month of examination, a numerical decrease was observed for all the species. This decrease was statistically significant only for Porphyromonas gingivalis (Wilcoxon Signed Ranks test, $\mathrm{P}<0.05$ ). At the 6 month re-examination, a statistically significant difference with baseline was observed in the experimental group for the Treponema denticola (Wilcoxon Signed Ranks test, $\mathrm{P}<0.05$ ), attributable to a further reduction in numbers of this species between the re-examinations. No statistically significant differences were found between the two groups at any time interval (Mann-Whitney test, $\mathrm{P}>0.05$ ).

The frequency distribution revealed an increase in the percentage of sites with less or equal to 105 microorganisms for Porphyromonas gingivalis, Tannerella forsythia and Treponema denticola and a subsequent decrease in the percentage of sites with more than 105 microorganisms (Table 6).

Table 5. Mean numbers $\left(\mathrm{x} 10^{5}\right.$, Mean \pm SEM) of the 3 microorganisms' species tested in various initial probing pocket depths at different examination intervals

\begin{tabular}{|c|c|c|c|c|c|c|c|}
\hline \multirow{2}{*}{$\begin{array}{c}\text { Micro- } \\
\text { organisms }\end{array}$} & \multirow{2}{*}{$\begin{array}{l}\text { Patients } \\
\text { Groups }\end{array}$} & \multicolumn{3}{|c|}{ Overall } & \multicolumn{3}{|c|}{ Initial PPD $>4 \mathrm{~mm}$} \\
\hline & & Baseline & 3 months & 6 months & Baseline & 3 months & 6 months \\
\hline \multirow{2}{*}{$P g$} & Control & $7.36 \pm 2.29$ & $2.63 \pm 0.72^{\mathrm{a}}$ & $1.39 \pm 0.44^{\mathrm{a}}$ & $7.97 \pm 0.24$ & $3.04 \pm 0.98^{\mathrm{a}}$ & $1.68 \pm 0.57$ \\
\hline & Experimental & $5.44 \pm 1.37$ & $3.28 \pm 0.82^{\mathrm{a}}$ & $2.49 \pm 0.65^{\mathrm{a}}$ & $5.97 \pm 1.27$ & $2.98 \pm 0.81^{\mathrm{a}}$ & $3.22 \pm 0.89^{\mathrm{a}}$ \\
\hline \multirow{2}{*}{$T f$} & Control & $4.20 \pm 1.57$ & $0.75 \pm 0.28$ & $0.83 \pm 0.24$ & $4.39 \pm 1.64$ & $0.95 \pm 0.42$ & $1.01 \pm 0.27$ \\
\hline & Experimental & $4.26 \pm 0.83$ & $1.77 \pm 0.49$ & $1.22 \pm 0.50$ & $4.78 \pm 0.96$ & $1.53 \pm 0.52$ & $1.81 \pm 0.63$ \\
\hline \multirow{2}{*}{$T d$} & Control & $3.03 \pm 1.54$ & $0.88 \pm 0.23$ & $0.74 \pm 0.38$ & $2.86 \pm 1.48$ & $0.99 \pm 0.34$ & $1.01 \pm 0.56$ \\
\hline & Experimental & $4.15 \pm 0.79$ & $1.75 \pm 0.59$ & $1.54 \pm 0.43^{\mathrm{a}}$ & $4.12 \pm 0.82$ & $2.17 \pm 0.75$ & $2.27 \pm 0.61$ \\
\hline
\end{tabular}

${ }^{a}$ Statistically significant difference from baseline (Wilcoxon Signed Ranks test, $\mathrm{P}<0.05$ ).

$P g=$ Porphyromonas gingivalis; $T f=$ Tannerella forsythia; $T d=$ Treponema denticola .

Table 6. Frequency distribution (\%) of sites depending on various microorganisms species concentration tested at different examination intervals

\begin{tabular}{clcccccc}
\hline \multirow{2}{*}{$\begin{array}{c}\text { Micro- } \\
\text { organisms }\end{array}$} & Patients Groups & Baseline & 3 months & 6 months & Baseline & 3 months & 6 months \\
\cline { 3 - 8 } \multirow{2}{*}{$\boldsymbol{P g}$} & Control & 58.3 & 74.4 & 85.4 & 41 & 25.6 & 14.6 \\
& Experimental & 46.2 & 71.8 & 77.1 & 53.8 & 28.2 & 22.9 \\
\hline \multirow{2}{*}{$\boldsymbol{T f}$} & Control & 61.1 & 87.5 & 81.0 & 38.9 & 12.5 & 19.0 \\
& Experimental & 63.4 & 85.3 & 72.3 & 36.6 & 14.7 & 27.7 \\
\hline \multirow{2}{*}{$\boldsymbol{T} \boldsymbol{d}$} & Control & 73.3 & 89.5 & 94.0 & 26.7 & 10.5 & 6.0 \\
& Experimental & 70.8 & 79.6 & 75.4 & 29.2 & 20.4 & 24.6 \\
\hline
\end{tabular}

$P g=$ Porphyromonas gingivalis; $T f=$ Tannerella forsythia $;$ Td = Treponema denticola. 
The results of further analysis that was performed for the sites that had initial PPD $>4 \mathrm{~mm}$, are presented in Table 5. A statistically significant decrease was found for Porphyromonas gingivalis in both groups at the 3 month examination (Wilcoxon Signed Ranks test, $\mathrm{P}<0.05$ ). No statistically significant differences were found between the two groups at any time interval (MannWhitney test, $\mathrm{P}>0.05$ )

\section{DISCUSSION}

The findings of the present study indicate that the adjunctive use of doxycycline failed to significantly improve the therapeutic outcome of mechanical treatment. In a previous study [11], the hand instruments were compared to the ultrasonics in the treatment of chronic periodontitis, but no difference was found between the two treatment modalities. The addition of locally delivered doxycycline in the treatment protocol of present study did not seem to offer any beneficial effect to the patients treated with ultrasonic debridement in comparison to the conventional hand instrumentation alone.

A marked reduction in every clinical parameter was observed for both treatment modalities in this study. Overall a statistically significant mean reduction in PPD of $0.88 \mathrm{~mm}$ and a mean CAL gain of $0.59 \mathrm{~mm}$ was recorded for the SRP group. The corresponding values for the UD + DOXY group were $0.92 \mathrm{~mm}$ and $0.31 \mathrm{~mm}$. The improvement was more pronounced for the moderate and the deep pockets. CAL scores at the 6 month re-examination did not show a statistically significant difference compared to baseline scores in the experimental group. In the deep pockets an additional, statistically significant, reduction was observed in PPD between 3 and 6 months. However no statistically significant differences were observed between the two groups. This could be explained by the fact that the test drug was applied to only 4 pre-selected pockets and therefore it would be very difficult to provide a true clinical benefit as the measurements were performed for the whole dentition.

The question of whether the adjunctive use of locally delivered antimicrobials to mechanical treatment offers an improved clinical and microbiological outcome over SRP alone remains unanswered. A number of studies have reported only limited improvement of CAL and PPD recordings when comparing the combined treatment protocol (SRP plus locally delivered antimicrobials) to conventional mechanical treatment alone [17-20]. Generally a PPD reduction of $1-1.5 \mathrm{~mm}$ in moderate pockets (4 - $6 \mathrm{~mm}$ of initial PPD) and of $2-2.5 \mathrm{~mm}$ in deeper sites has to be expected after mechanical root instrumentation [21-26]. This occurs concomitantly with a CAL gain of approximately $0.5 \mathrm{~mm}$ and $1.5 \mathrm{~mm}$ in the moderate and the deep pockets respectively. Any additional pocket reduction or CAL gain, following the administration of the drug, would therefore represent a true clinical benefit and hence may reduce the need for additional periodontal surgery.

Previously published studies referring on the utilization of locally delivered doxycycline polymer focused on its effects when used as a monotherapy. Comparable efficacy of the 2 treatments in the terms of reduction in pocket depth and gain in clinical attachment level was reported in two parallel multicenter studies comparing the locally delivered doxycycline to the SRP alone [2]. In another multicenter study, tetracycline showed a small but significant advantage over scaling and root planing [27].

Heijl et al. [28] using a split mouth design, observed changes in probing depth comparable to this study for each treatment. The difference between the responses to scaling alone and scaling combined with tetracycline fibers were small and not statistically significant. In a systematic review [10], the reviewers generally found modest differences for PPD favouring the combined treatment. These, even when statistically significant, ranged from $0.1 \mathrm{~mm}$ to $0.5 \mathrm{~mm}$, and were of little clinical importance. Effects for CAL gains were smaller and statistical significance was less common.

In very accurately designed study [29] two different approaches were evaluated for the non-surgical treatment of moderate periodontal pockets. Traditional SRP was compared to ultrasonic debridement followed by $8.5 \%$ doxycycline hyclate administration in sites deeper than $5 \mathrm{~mm}$. At the 3 month examination better results regarding PPD and CAL were observed in the ultrasonic debridement group than in the SRP group. A retreatment of non-responding sites (PPD $>5 \mathrm{~mm}$ ) consisting of ultrasonic debridement combined with doxycycline application in the SRP group at this time point lead to a similar clinical outcome for both groups 6 months after baseline. Taking into account the reduced time needed for ultrasonic treatment the authors concluded that simplified, subgingival debridement in conjuction with doxycycline application could be a justified approach for deeper periodontal pockets.

Although, in the present study the time required for the instrumentation was not specifically recorded, the therapists felt that ultrasonic debridement was less time consuming than hand instrumentation. The patient-centered outcome variables, like reduced treatment time, are considered of importance in the evaluation of treatment outcome today. Simplified, less time and effort demanding procedures like ultrasonic debridement combined with locally delivered 
antimicrobials, i.e. doxycycline hyclate, could represent a reliable alternative in treating moderate periodontal pockets or can be an option for patients where a surgical intervention is not indicated. In this respect the findings of the present study are in accordance with those of the Wennstrom et al. study [29].

Adjunct use of the locally delivered drugs seems to have a beneficial effect in smokers and in retreatment of the patients with persisting periodontal pockets. The adjunctive use of locally delivered doxycycline in smokers may offer some benefit for the active and supportive periodontal treatment in both clinical $[30,31]$ and microbiological findings $[\underline{32}, 33]$. Initial studies on maintenance patients have shown that the local application of tetracyclines seems to offer improved results [19-34], although more recent data failed to support those findings $[\underline{35}, \underline{36}]$. In accordance with that, Tomasi et al. [37] concluded that locally delivered doxycycline failed to improve the healing outcome following the re-instrumentation with a piezo-ceramic ultrasonic device of periodontal pockets with posttherapeutic depth greater or equal to $5 \mathrm{~mm}$.

At the 3 month re-examination both therapeutic approaches resulted in a statistically significant reduction of the number of Porphyromonas gingivalis only. A profound, yet not statistically significant, reduction was observed for Tannerella forsythia and Treponema denticola as well, but in no case was eradication of the periopathogenic species found. Following the administration of drug, an adjunct effect of doxycycline on the presence of Treponema denticola was observed after 6 months in the experimental group.

In the present study no statistically significant differences were observed between the two groups regarding the microbiological parameters. The findings are in accordance with earlier studies comparing scaling and root planing alone with scaling and root planing followed by the application of locally delivered drugs in initial [38,39] and supportive periodontal treatment [35]. In contrast, Goodson et al. [40] in a large, multicenter trial showed a greater reduction in the numbers and proportions of red complex bacteria following the adjunctive use of minocycline microspheres.

In order to be effective antimicrobials must reach their target site and be maintained there in sufficient concentrations long enough for their antimicrobial effect to occur [ $\underline{8}$ ]. The concentration required for efficacy is often estimated from the minimum inhibitory concentration (MIC), although this has substantial shortcomings; in particular, the fact that MIC is assessed in vitro whereas the drug is active in vivo in a constantly changing host environment. Other problems related to estimating effective drug concentrations in vivo are the large number of periodontal subgingival organisms and the large variation in the MICs of isolates [41]. Defining the minimally effective concentration is complex and most dosages are based on in vitro experiments in which bacteria were grown under planktonic conditions. It is known that bacteria are organized into biofilms when present in the periodontal pocket. These biofilms will probably require a significantly higher concentration of antimicrobial to kill those bacteria where Cargill et al. [42] found that legionellae in biofilms were 135 times more resistant to iodination when compared to microorganisms growing in non-organised or planktonic fashion [42-44]. This is a strong indication that locally delivered antimicrobials should be used adjunctively with mechanical instrumentation to disrupt the biofilms. A concern in the use of antimicrobials in the treatment of chronic periodontitis is the risk for the emergence of an antibiotic-resistant complex of species. This issue in relation to the use of locally applied, sustained-release doxycycline was evaluated in a recent study of Walker et al. [45]. It was concluded that doxycycline treatment did not result in a change of actual number of resistant bacteria or in the acquisition of antibiotic resistance.

\section{CONCLUSIONS}

According to the findings of present study the adjunctive use of locally delivered doxycycline did not seem to add any beneficial effect to the active treatment of chronic periodontitis. Only in deep pockets an additional improvement was observed between 3 and 6 months in the experimental group, which however was not strong enough to provide a statistically significant difference between the two groups. In conclusion, it is suggested that more long-term studies focusing on the outcome of the combined therapy during supportive periodontal treatment are needed, where more favourable results could be expected, especially in the case of deep pockets.

\section{ACKNOWLEDGMENTS AND DISCLOSURE STATEMENTS}

The authors declare that they have no conflict of interests. There was no external source of funding for the study. 


\section{REFERENCES}

1. Haffajee AD, Socransky SS, Gunsolley JC. Systemic anti-infective periodontal therapy. A systematic review. Ann Periodontol. 2003 Dec;8(1):115-81. Review. [Medline: 14971252] [doi: 10.1902/annals.2003.8.1.115]

2. Garrett S, Johnson L, Drisko CH, Adams DF, Bandt C, Beiswanger B, Bogle G, Donly K, Hallmon WW, Hancock EB, Hanes P, Hawley CE, Kiger R, Killoy W, Mellonig JT, Polson A, Raab FJ, Ryder M, Stoller NH, Wang HL, Wolinsky LE, Evans GH, Harrold CQ, Arnold RM, Southard GL, et al. Two multi-center studies evaluating locally delivered doxycycline hyclate, placebo control, oral hygiene, and scaling and root planing in the treatment of periodontitis. J Periodontol. 1999 May;70(5):490-503. [Medline: 10368053] [doi: 10.1902/jop.1999.70.5.490]

3. Kaldahl WB, Kalkwarf KL, Patil KD, Dyer JK, Bates RE Jr. Evaluation of four modalities of periodontal therapy. Mean probing depth, probing attachment level and recession changes. J Periodontol. 1988 Dec;59(12):783-93. [Medline: 3066888 ]

4. Drisko CH. Nonsurgical periodontal therapy. Periodontol 2000. 2001;25:77-88. Review. [Medline: 11155183] [doi: 10.1034/j.1600-0757.2001.22250106.x]

5. Tunkel J, Heinecke A, Flemmig TF. A systematic review of efficacy of machine-driven and manual subgingival debridement in the treatment of chronic periodontitis. J Clin Periodontol. 2002;29 Suppl 3:72-81; discussion 90-1. Review. [Medline: 12787208] [doi: 10.1034/j.1600-051X.29.s3.4.x]

6. Hallmon WW, Rees TD. Local anti-infective therapy: mechanical and physical approaches. A systematic review. Ann Periodontol. 2003 Dec;8(1):99-114. Review. [Medline: 14971251] [doi: 10.1902/annals.2003.8.1.99]

7. Hanes PJ, Purvis JP. Local anti-infective therapy: pharmacological agents. A systematic review. Ann Periodontol. 2003 Dec;8(1):79-98. Review. [Medline: 14971250] [doi: 10.1902/annals.2003.8.1.79]

8. Goodson JM. Pharmacokinetic principles controlling efficacy of oral therapy. J Dent Res. 1989;68 (Special Issue):1625-32.

9. Quirynen M, Teughels W, De Soete M, van Steenberghe D. Topical antiseptics and antibiotics in the initial therapy of chronic adult periodontitis: microbiological aspects. Periodontol 2000. 2002;28:72-90. Review. [Medline: 12013349] [doi: $10.1034 / j .1600-0757.2002 .280104 . x$ ]

10. Bonito AJ, Lux L, Lohr KN. Impact of local adjuncts to scaling and root planing in periodontal disease therapy: a systematic review. J Periodontol. 2005 Aug;76(8):1227-36. Review. Erratum in: J Periodontol. 2006 Feb;77(2):326. [Medline: 16101353] [doi: 10.1902/jop.2005.76.8.1227]

11. Ioannou I, Dimitriadis N, Papadimitriou K, Sakellari D, Vouros I, Konstantinidis A. Hand instrumentation versus ultrasonic debridement in the treatment of chronic periodontitis: a randomized clinical and microbiological trial. J Clin Periodontol. 2009 Feb;36(2):132-41. [Medline: 19207889] [doi: 10.1111/j.1600-051X.2008.01347.x]

12. Armitage GC. Development of a classification system for periodontal diseases and conditions. Ann Periodontol. 1999 Dec;4(1):1-6. Review. [Medline: 10863370] [doi: 10.1902/annals.1999.4.1.1]

13. Carter HG, Barnes GP. The Gingival Bleeding Index. J Periodontol. 1974 Nov;45(11):801-5. [Medline: 4547795]

14. O'Leary TJ, Drake RB, Naylor JE. The plaque control record. J Periodontol. 1972 Jan;43(1):38. [Medline: 4500182]

15. Socransky SS, Smith C, Martin L, Paster BJ, Dewhirst FE, Levin AE. "Checkerboard" DNA-DNA hybridization. Biotechniques. 1994 Oct;17(4):788-92. [Medline: 7833043]

16. Altman DG, Schulz KF, Moher D, Egger M, Davidoff F, Elbourne D, Gøtzsche PC, Lang T; CONSORT GROUP (Consolidated Standards of Reporting Trials). The revised CONSORT statement for reporting randomized trials: explanation and elaboration. Ann Intern Med. 2001 Apr 17;134(8):663-94. Review [Medline: 11304107]

17. Graça MA, Watts TL, Wilson RF, Palmer RM. A randomized controlled trial of a $2 \%$ minocycline gel as an adjunct to nonsurgical periodontal treatment, using a design with multiple matching criteria. J Clin Periodontol. 1997 Apr;24(4):249-53. [Medline: 9144047] [doi: 10.1111/j.1600-051X.1997.tb01838.x]

18. Tonetti MS, Cortellini P, Carnevale G, Cattabriga M, de Sanctis M, Pini Prato GP. A controlled multicenter study of adjunctive use of tetracycline periodontal fibers in mandibular class II furcations with persistent bleeding. J Clin Periodontol. 1998 Sep;25(9):728-36. [Medline: 9763328] [doi: 10.1111/j.1600-051X.1998.tb02514.x]

19. Kinane DF, Radvar M. A six-month comparison of three periodontal local antimicrobial therapies in persistent periodontal pockets. J Periodontol. 1999 Jan;70(1):1-7. [Medline: 10052765] [doi: 10.1902/jop.1999.70.1.1]

20. Van Dyke TE, Offenbacher S, Braswell L, Lessem J. Enhancing the value of scaling and root-planing: Arestin clinical trial results. J Int Acad Periodontol. 2002 Jul;4(3):72-6. [Medline: 12670085]

21. Morrison EC, Ramfjord SP, Hill RW. Short-term effects of initial, nonsurgical periodontal treatment (hygienic phase). J Clin Periodontol. 1980 Jun;7(3):199-211. [Medline: 7000853] [doi: 10.1111/j.1600-051X.1980.tb01963.x]

22. Badersten A, Nilvéus R, Egelberg J. Effect of nonsurgical periodontal therapy. I. Moderately advanced periodontitis. J Clin Periodontol. 1981 Feb;8(1):57-72. [Medline: 6972954] [doi: 10.1111/j.1600-051X.1981.tb02024.x]

23. Badersten A, Nilveus R, Egelberg J. Effect of nonsurgical periodontal therapy. II. Severely advanced periodontitis. J Clin Periodontol. 1984 Jan;11(1):63-76. [Medline: 6363463] [doi: 10.1111/j.1600-051X.1984.tb01309.x]

24. Hill RW, Ramfjord SP, Morrison EC, Appleberry EA, Caffesse RG, Kerry GJ, Nissle RR. Four types of periodontal treatment compared over two years. J Periodontol. 1981 Nov;52(11):655-62. [Medline: 7028941] 
25. Pihlstrom BL, McHugh RB, Oliphant TH, Ortiz-Campos C. Comparison of surgical and nonsurgical treatment of periodontal disease. A review of current studies and additional results after 61/2 years. J Clin Periodontol. 1983 Sep;10(5):524-41. [Medline: 6355204] [doi: 10.1111/j.1600-051X.1983.tb02182.x]

26. Westfelt E, Bragd L, Socransky SS, Haffajee AD, Nyman S, Lindhe J. Improved periodontal conditions following therapy. J Clin Periodontol. 1985 Apr;12(4):283-93. [Medline: 3889071] [doi: 10.1111/j.1600-051X.1985.tb02294.x]

27. Goodson JM, Cugini MA, Kent RL, Armitage GC, Cobb CM, Fine D, Fritz ME, Green E, Imoberdorf MJ, Killoy WJ, et al. Multicenter evaluation of tetracycline fiber therapy: II. Clinical response. J Periodontal Res. 1991 Jul;26(4):371-9. [Medline: 1831505] [doi: 10.1111/j.1600-0765.1991.tb02076.x]

28. Heijl L, Dahlen G, Sundin Y, Wenander A, Goodson JM. A 4-quadrant comparative study of periodontal treatment using tetracycline-containing drug delivery fibers and scaling. J Clin Periodontol. 1991 Feb;18(2):111-6. [Medline: 2005224] [doi: 10.1111/j.1600-051X.1991.tb01699.x]

29. Wennström JL, Newman HN, MacNeill SR, Killoy WJ, Griffiths GS, Gillam DG, Krok L, Needleman IG, Weiss G, Garrett S. Utilisation of locally delivered doxycycline in non-surgical treatment of chronic periodontitis. A comparative multi-centre trial of 2 treatment approaches. J Clin Periodontol. 2001 Aug;28(8):753-61. English, French, German. [Medline: 11442735] [doi: 10.1034/j.1600-051X.2001.280806.x]

30. Tomasi C, Wennström JL. Locally delivered doxycycline improves the healing following non-surgical periodontal therapy in smokers. J Clin Periodontol. 2004 Aug;31(8):589-95. [Medline: 15257733] [doi: 10.1111/j.1600-051X.2004.00524.x]

31. Machion L, Andia DC, Lecio G, Nociti FH Jr, Casati MZ, Sallum AW, Sallum EA. Locally delivered doxycycline as an adjunctive therapy to scaling and root planing in the treatment of smokers: a 2-year follow-up. J Periodontol. 2006 Apr;77(4):606-13. [Medline: 16584341] [doi: 10.1902/jop.2006.050087]

32. Machion L, Andia DC, Saito D, Klein MI, Gonçalves RB, Casati MZ, Nociti FH Jr, Sallum EA. Microbiological changes with the use of locally delivered doxycycline in the periodontal treatment of smokers. J Periodontol. 2004 Dec;75(12):1600-4. [Medline: 15732860] [doi: 10.1902/jop.2004.75.12.1600]

33. Shaddox LM, Andia DC, Casati MZ, Nociti FH Jr, Sallum EA, Gollwitzer J, Walker CB. Microbiologic changes following administration of locally delivered doxycycline in smokers: a 15-month follow-up. J Periodontol. 2007 Nov;78(11):2143-9. [Medline: 17970681] [doi: 10.1902/jop.2007.070189]

34. Meinberg TA, Barnes CM, Dunning DG, Reinhardt RA. Comparison of conventional periodontal maintenance versus scaling and root planing with subgingival minocycline. J Periodontol. 2002 Feb;73(2):167-72. [Medline: 11895281] [doi: 10.1902/jop.2002.73.2.167]

35. Bogren A, Teles RP, Torresyap G, Haffajee AD, Socransky SS, Wennström JL. Locally delivered doxycycline during supportive periodontal therapy: a 3-year study. J Periodontol. 2008 May;79(5):827-35. [Medline: 18454661] [doi: 10.1902/jop.2008.070515]

36. Dannewitz B, Lippert K, Lang NP, Tonetti MS, Eickholz P. Supportive periodontal therapy of furcation sites: non-surgical instrumentation with or without topical doxycycline. J Clin Periodontol. 2009 Jun;36(6):514-22. [Medline: 19508250] [doi: 10.1111/j.1600-051X.2009.01414.x]

37. Tomasi C, Koutouzis T, Wennström JL. Locally delivered doxycycline as an adjunct to mechanical debridement at retreatment of periodontal pockets. J Periodontol. 2008 Mar;79(3):431-9. [Medline: 18315425] [doi: 10.1902/jop.2008.070383]

38. Timmerman MF, van der Weijden GA, van Steenbergen TJ, Mantel MS, de Graaff J, van der Velden U. Evaluation of the long-term efficacy and safety of locally-applied minocycline in adult periodontitis patients. J Clin Periodontol. 1996 Aug;23(8):707-16. [Medline: $\underline{\text { 8877655] [doi: 10.1111/j.1600-051X.1996.tb00599.x] }}$

39. Jorgensen MG, Safarian A, Daneshmand N, Keim RJ, Slots J. Initial antimicrobial effect of controlledrelease doxycycline in subgingival sites. J Periodontal Res. 2004 Oct;39(5):315-9. [Medline: 15324352] [doi: $0.1111 / j .1600-0765.2004 .00742 . x$ ]

40. Goodson JM, Gunsolley JC, Grossi SG, Bland PS, Otomo-Corgel J, Doherty F, Comiskey J. Minocycline HCl microspheres reduce red-complex bacteria in periodontal disease therapy. J Periodontol. 2007 Aug;78(8):1568-79. [Medline: 17668977] [doi: 10.1902/jop.2007.060488]

41. Walker CB, Pappas JD, Tyler KZ, Cohen S, Gordon JM. Antibiotic susceptibilities of periodontal bacteria. In vitro susceptibilities to eight antimicrobial agents. J Periodontol. 1985 Nov;56(11 Suppl):67-74. [Medline: 3866054$]$

42. Cargill KL, Pyle BH, Sauer RL, McFeters GA. Effects of culture conditions and biofilm formation on the iodine susceptibility of Legionella pneumophila. Can J Microbiol. 1992 May;38(5):423-9. Erratum in: Can J Microbiol 1992 Oct;38(10):1089. [Medline: 1643585] [doi: 10.1139/m92-071]

43. Vorachit M, Lam K, Jayanetra P, Costerton JW. Resistance of Pseudomonas pseudomallei growing as a biofilm on silastic discs to ceftazidime and co-trimoxazole. Antimicrob Agents Chemother. 1993 Sep;37(9):2000-2. [Medline: 7694545] [FREE Full Text]

44. Wright TL, Ellen RP, Lacroix JM, Sinnadurai S, Mittelman MW. Effects of metronidazole on Porphyromonas gingivalis biofilms. J Periodontal Res. 1997 Jul;32(5):473-7. [Medline: 9266499] [doi: 10.1111/j.1600-0765.1997.tb00560.x]

45. Walker CB, Godowski KC, Borden L, Lennon J, Nangó S, Stone C, Garrett S. The effects of sustained release doxycycline on the anaerobic flora and antibiotic-resistant patterns in subgingival plaque and saliva. J Periodontol. 2000 May;71(5):768-74. [Medline: 10872958 ] [doi: $10.1902 /$ jop.2000.71.5.768] 


\section{To cite this article:}

Ioannou I, Dimitriadis N, Papadimitriou K, Vouros I, Sakellari D, Konstantinidis A. The Effect of Locally Delivered Doxycycline in the Treatment of Chronic Periodontitis. A Clinical and Microbiological Cohort Study.

J Oral Maxillofac Res 2010;1(4):e1

URL: http://www.ejomr.org/JOMR/archives/2010/4/e1/v1n4e1ht.pdf

doi: $10.5037 /$ jomr.2010.1401

Copyright (C) Ioannou I, Dimitriadis N, Papadimitriou K, Vouros I, Sakellari D, Konstantinidis A. Accepted for publication in the JOURNAL OF ORAL \& MAXILLOFACIAL RESEARCH (http://www.ejomr.org/), 31 July 2010.

This is an open-access article, first published in the JOURNAL OF ORAL \& MAXILLOFACIAL RESEARCH, distributed under the terms of the Creative Commons Attribution-Noncommercial-No Derivative Works 3.0 Unported License, which permits unrestricted non-commercial use, distribution, and reproduction in any medium, provided the original work and is properly cited. The copyright, license information and link to the original publication on (http://www.ejomr.org/) must be included. 